\title{
Assessment of Forest Cover Conditions and Canopy Density using Remote Sensing and GIS Techniques in Parts of Jharkhand State
}

\author{
Jai Kumar ${ }^{1}$, Paras Talwar ${ }^{2}$, A. P. Krishna ${ }^{3}$ \\ ${ }^{1}$ Department of Remote Sensing, Birla Institute of Technology Ranchi, Bihar, India \\ ${ }^{2}$ Department of Remote Sensing, Birla Institute of Technology Ranchi, Delhi, India \\ ${ }^{3}$ Department of Remote Sensing, Birla Institute of Technology Ranchi, Ranchi, India \\ *Corresponding Author: Jai Kumar, Department of Remote Sensing, Birla Institute of Technology \\ Ranchi, Bihar, India
}

Received Date: 17-04-2017

Accepted Date: 16-06-2017

Published Date: 24-06-2017

\begin{abstract}
A Landsat 8 satellite image was used for preparing forest cover mapping and derived the Normalized Difference Vegetation Index (NDVI) in Arc GIS 10. The Supervised Classification on Landsat 8 image was done whose Kappa statistics are carried out in ERDAS Image 9.2. The correlation has been enumerate between Forest cover Density and mean NDVI (using R statistical software), which comes out to be good and also between average Elevation (which comes out through ASTER DEM data) and Forest cover Density comes out to be not to good. This model calculates forest canopy density using the three indices of bare soil index (BSI), shadow index (SI) and vegetation index. the forest map was prepared by using forest canopy density modeling whose overall accuracy is 86 to $90 \%$. The correlation is calculated between forest cover density and forest canopy density which comes out to be not to good also between average elevation and forest canopy density comes out to be good.
\end{abstract}

Keywords: Landsat 8, Remote sensing, Deforestation, forest, NDVI, ASTER DEM, Correlation, FCD

\section{INTRODUCTION}

Forest stands or cover types consisting of a plant community made up of trees and other woody vegetation, growing more or less closely together. Therefore, there scope for intensity of forest cover. It becomes compulsory to monitor current status of forest .Understanding of altitudinal variation of forest cover density in Jharkhand state area. Thus plays a major role in this context. The forest cover condition defines land cover classification and various altitudinal ranges with forest cover density. Forest density expressing the stocking status buildup single major stand physiognomic character of forest .So for the scientific forest management, the knowledge of forest density classes is necessary at the local, regional, state and national levels purposes.

Forest canopy cover, also known as canopy coverage or crown cover, is defined as the proportion of forest floor covered by the vertical projection of the tree crowns. The anthropogenic intervention in the natural for reduces the number of tree per unit area and canopy closure. Forest canopy density is one of the most useful parameter to consider in planning and implementation of rehabilitation program.

Remote sensing is a very powerful tool in the provision of such information it involves the acquisition of information about object, area or phenomenon through the analysis of data acquired by a device that is not in contact with the object, phenomenon or area under investigation Remote sensing technique to know the forest condition areas of Jharkhand India. Forest plays an important role in global carbon cycles. Forest conversion is the second largest global source of anthropogenic carbon dioxide emissions. Satellite remote sensing has played Pivotal role in generating information about forest cover, vegetation type and land use change.

\section{Objectives of study}

To assess the forest cover condition and forest canopy density of the study area.

To establish relationship between topographic variables and forest cover condition in the study area.

To assess the relationship between vegetation indices and forest cover density. 
Assessment of Forest Cover Conditions and Canopy Density using Remote Sensing and GIS Techniques in Parts of Jharkhand State

\section{Study Area}

The study area is Jharkhand state which lies between $\quad 22^{\circ} 00^{\prime} \& 2437^{\prime}$ North latitude and $83^{\circ} 15^{\prime} \& 87^{\circ}$ 01' East longitude.

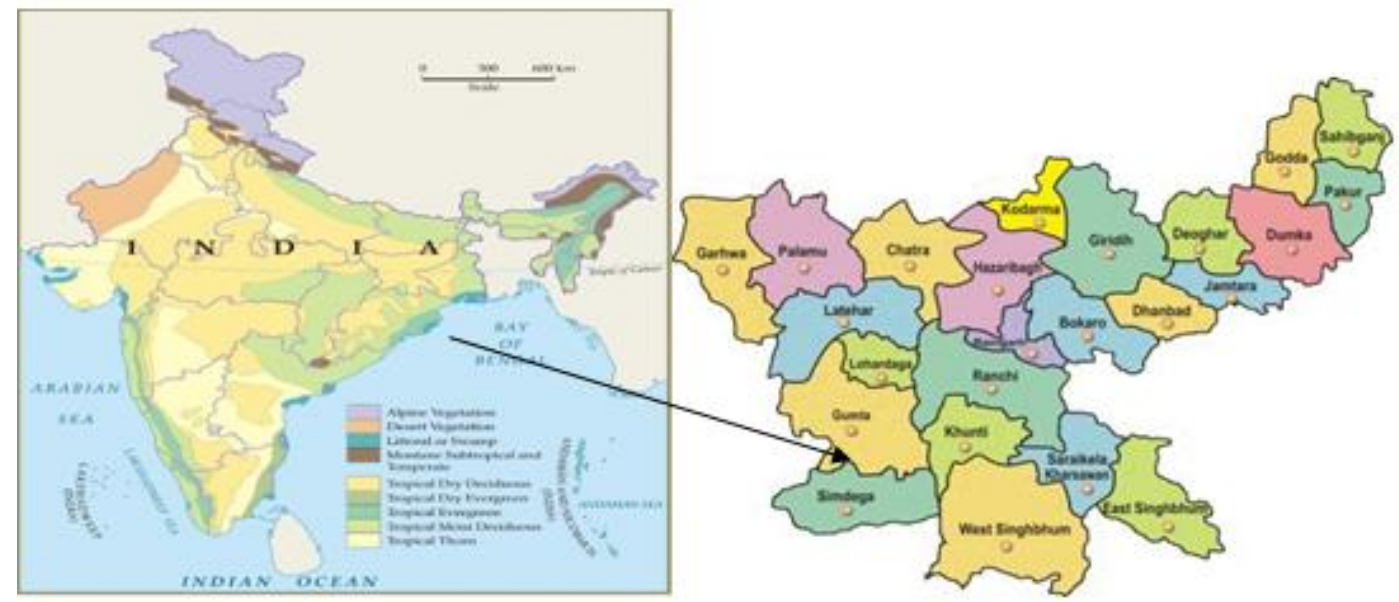

Figure1. Study Area

\section{Data Used}

Satellite Imagery - Landsat 8 (OLI) November, 2013, USGS, Aster DEM

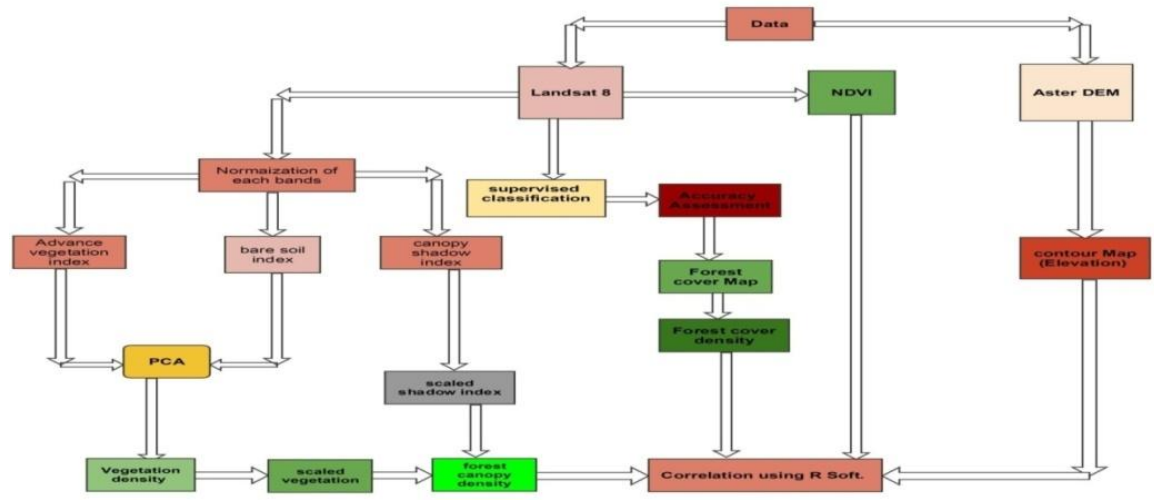

Figure2.Flow chart of methodology

\section{METHODOLGY STEPS}

\section{Forest Cover Density}

Forest classification(Supervised Classification) is carried out by digital image processing techniques in Erdas Imagine 9.2 . The classified image have four classes i.e. Forest, Fallow Land, Agriculture Land ,Water Body, BuiltUp/Mining.

The classified image is now going through Kappa statistical test i.e Accuracy assessment using Erdas Imagine 9.2.

After that we have calculated the Forest Area in $\mathrm{Sq} \mathrm{Km}$. The classified image is then used in Arc-GIS 10 to represent the forest cover through Map. At the end we have calculated Forest Cover Density. Forest Cover Density $(\%)=$ (Forest Cover Area/Total Land Area)*100

\section{Altitudinal Calculation}

Now I have to take ASTER DEM data and clipped out our study area.

Contour map is generated in Arc-GIS to determine the altitude of each districts in Jharkhand.

\section{Normalized Difference Vegetation Index (NIVII)}

The NDVI ratio is calculated by dividing the difference in the near-infrared (NIR) and red color bands by the sum of the NIR and red colors bands for each pixel in the image as follows.

$\mathrm{NDVI}=(\mathrm{NIR}-\mathrm{RED}) /(\mathrm{NIR}+\mathrm{RED})$ 
Assessment of Forest Cover Conditions and Canopy Density using Remote Sensing and GIS Techniques in Parts of Jharkhand State

\section{Correlation in R Statistical Software}

\section{Forest Density with Mean NDVI}

The following steps are followed in R software window i.e.

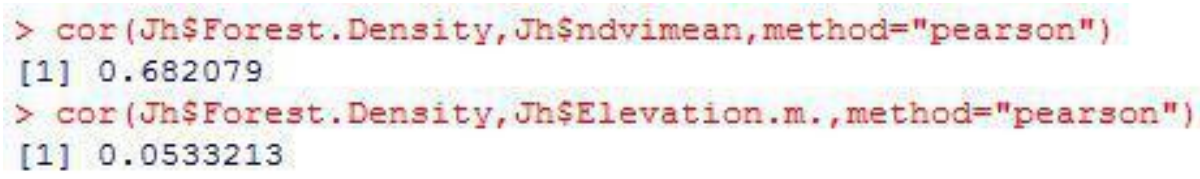

The LANDSAT 8 bands were normalized using linear transformation (equations 1 and 2)

$$
\begin{aligned}
& \mathrm{A}=(\mathrm{Y} 1-\mathrm{Y} 2) /(\mathrm{X} 1-\mathrm{X} 2)=20-65520 /(\mathrm{M}-2 \mathrm{~S})-(\mathrm{M}+2 \mathrm{~S}) \\
& \mathrm{B}=-\mathrm{AX} 1+\mathrm{Y} 1 \\
& \mathrm{Y}=\mathrm{AX}+\mathrm{B}
\end{aligned}
$$

Where: $\mathrm{X} 1=\mathrm{M}-2 \mathrm{~S} \quad \mathrm{X} 2=\mathrm{M}+2 \mathrm{~S} \quad \mathrm{Y} 1=20$

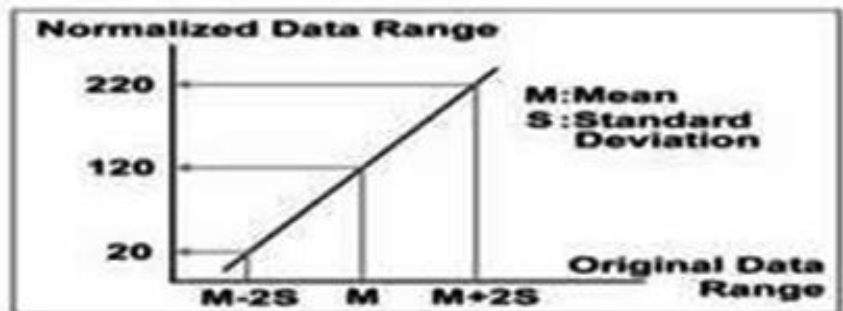

$\mathrm{Y} 2=65520 \mathrm{M}=\mathrm{Mean} \mathrm{S}=$ Standard deviation

$\mathrm{X}=$ Original data $\mathrm{Y}=$ normalization data

Apply Normalization on each band i.e. 2, 3, 4,5,6,7 Bands

\section{Advance vegetation Index}

NDVI is unable to high-light delicately balanced amount in cover relation between Mass and size. For this reason, it has been getting better by using power degree of the infrared response.

The calculated index has been termed as an advanced vegetation index (AVI). AVI has been worked out Using an equation.

$\mathrm{AVI}=\{(\mathrm{B} 5+1)(65536-\mathrm{B} 4)(\mathrm{B} 5-\mathrm{B} 4)] 1 / 3$

$\mathrm{AVI}=0$ If $\mathrm{B} 5<\mathrm{B} 4$ after normalization

\section{Bare Soill Index (BSI)}

This index helps us to give clear idea of vegetation from the surrounding. Its equation

$\mathrm{BIO}=((\mathrm{B} 5+\mathrm{B} 3)-(\mathrm{B} 4+\mathrm{B} 1)) /((\mathrm{B} 5+\mathrm{B} 3)+$ (B4+B1))

$\mathrm{BI}=\mathrm{BIO} * 100+100$

\section{Canopy Shadow Index (SI)}

This index works out with a shadow pattern affecting the spectral response when the crown arrangement in any forest. It shows a low canopy shadow index in the case of young even aged as compared to mature natural forest.
$\mathrm{SI}=((65536-\mathrm{B} 2) *(65536-\mathrm{B} 3) *(65536-\mathrm{B} 4))$

$1 / 3$

\section{Vegetation density}

This is determined by yield through principal component analysis (PCA 1) between AVI and $\mathrm{BI}$ as these two parameters have a high correlation of negative. Then it is scaled from 0 to 100 to form Scaled Vegetation Density (SVD).

\section{Scalled Shadow Index}

Before going to scale 0 to 100 to form SSI first we have to normalize the SI so that we utilize the other parameters. SSI $100 \%$ represents the highest possible shadow whereas $0 \%$ represents the opposite.

\section{Forest Canopy Density (FCD)}

It is synthesis by using SSI and SVD and also both indices are scaled and unit of Each produces Forest Canopy Density by using

$\mathrm{FCD}=((\mathrm{SVD} * \mathrm{SSI})+1) 1 / 2-1$ 
Assessment of Forest Cover Conditions and Canopy Density using Remote Sensing and GIS Techniques in Parts of Jharkhand State

Correlation in R Statistical Software

1) Forest canopy Density with Mean NDVI / Forest cover density and elevation:

The following steps are followed in R software Window i.e.

$>\operatorname{cor}$ (JHSForest.Canopy. Density, JHSForest.Cover.Density)

[1] 0.3330436

$>\operatorname{cor}$ (JHSForest.Canopy.Density, JH\$Elevation.m.)

[1] 0.5500228

$>\operatorname{cor}$ (JHŞForest. Canopy. Density, JH\$̣NdviMean)

[1] 0.1866475

\section{RESUlTS \& DisCUSSION}
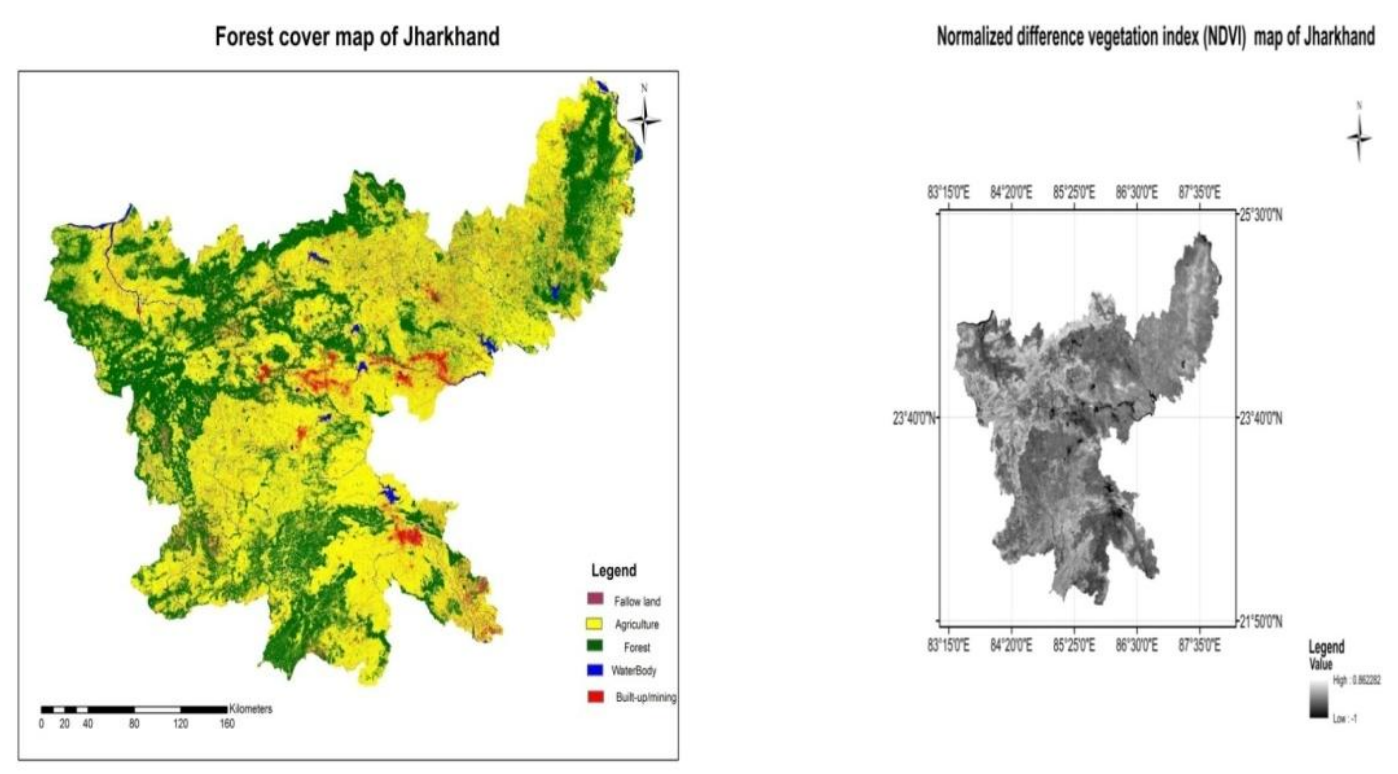

Contour map of Jharkhand
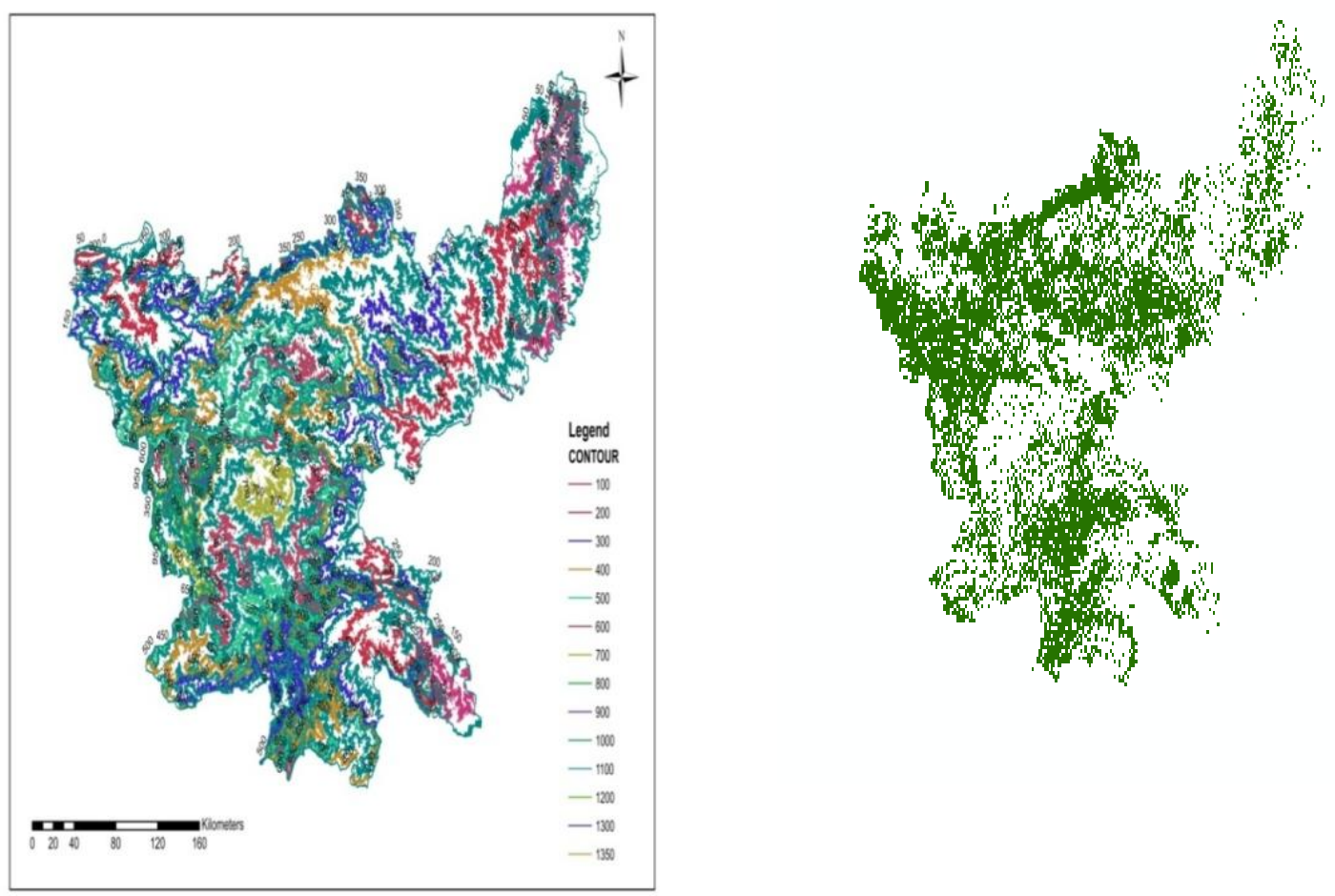

Figure3. Forest map, NDVI map, contour map and forest canopy map of Jharkhand 
Assessment of Forest Cover Conditions and Canopy Density using Remote Sensing and GIS Techniques in Parts of Jharkhand State

Correlation of Average Elevation, Mean Ndvi \& Forest Cover Density of Different Districts of Jharkhand

\begin{tabular}{|c|c|c|c|c|c|c|}
\hline & District & Total.Area & Total.Forest & Forest.Density & Elevation.m. & ndvimean \\
\hline 1 & Ranchi & 3841.62 & 774.7224 & 20.16655 & 525 & 0.2817736 \\
\hline 2 & Lohardaga & 1496 & 518.98 & 34.69118 & 550 & 0.2906081 \\
\hline 3 & Gumla & 5340.6 & 1590.54 & 29.78205 & 550 & 0.2893403 \\
\hline 5 & Palamu & 4429.96 & 1591 & 35.91455 & 325 & 0.2899677 \\
\hline 6 & Latehar & 4254 & 2319.22 & 54.51857 & 575 & 0.3139274 \\
\hline 7 & Garhwa & 4050 & 2022.343 & 49.93441 & 575 & 0.3005241 \\
\hline 10 & East singhbhum & 3562.98 & 714.95 & 20.06607 & 450 & 0.2786901 \\
\hline 11 & Dumka & 3738 & 1437.97 & 38.46897 & 225 & 0.3044571 \\
\hline 12 & Jamtara & 1772.46 & 277.75 & 15.67031 & 175 & 0.2877612 \\
\hline 13 & Sahebganj & 2175.94 & 960.16 & 44.12622 & 225 & 0.2997219 \\
\hline 14 & Pakur & 1794 & 833.34 & 46.45151 & 275 & 0.2940202 \\
\hline 15 & Godda & 2218.8 & 658.8701 & 29.69488 & 275 & 0.303972 \\
\hline 20 & Dhanbad & 2071.74 & 454.63 & 21.94436 & 325 & 0.2982494 \\
\hline 21 & Bokaro & 2830 & 497.26 & 17.57102 & 325 & 0.2765598 \\
\hline 22 & Deoghar & 3980 & 363.8032 & 9.140784 & 350 & 0.3006745 \\
\hline 23 & Khunti & 3792 & 959.76 & 25.31013 & 425 & 0.2919872 \\
\hline
\end{tabular}

Figure4. Result in R (STATISTICAL SOFTWARE)

Land use /land cover \& forest cover has been done using pattern recognition, viz. supervised classification. The forest cover density was calculated using following equation.DEM was classified in different altitudinal rang. The forest cover density was compare with mean normalization difference vegetation index (NDVI).The above result clarifies that they are positive $(0.68)$ relation between Forest cover density and NDVI where as the relation between Elevation and Forest Cover density is not up to our expected value (0.036).

Correlation of Average Elevation, Mean Ndvi \& Forest Cover Density, Forest Canopy Density of Different Districts of Jharkhand

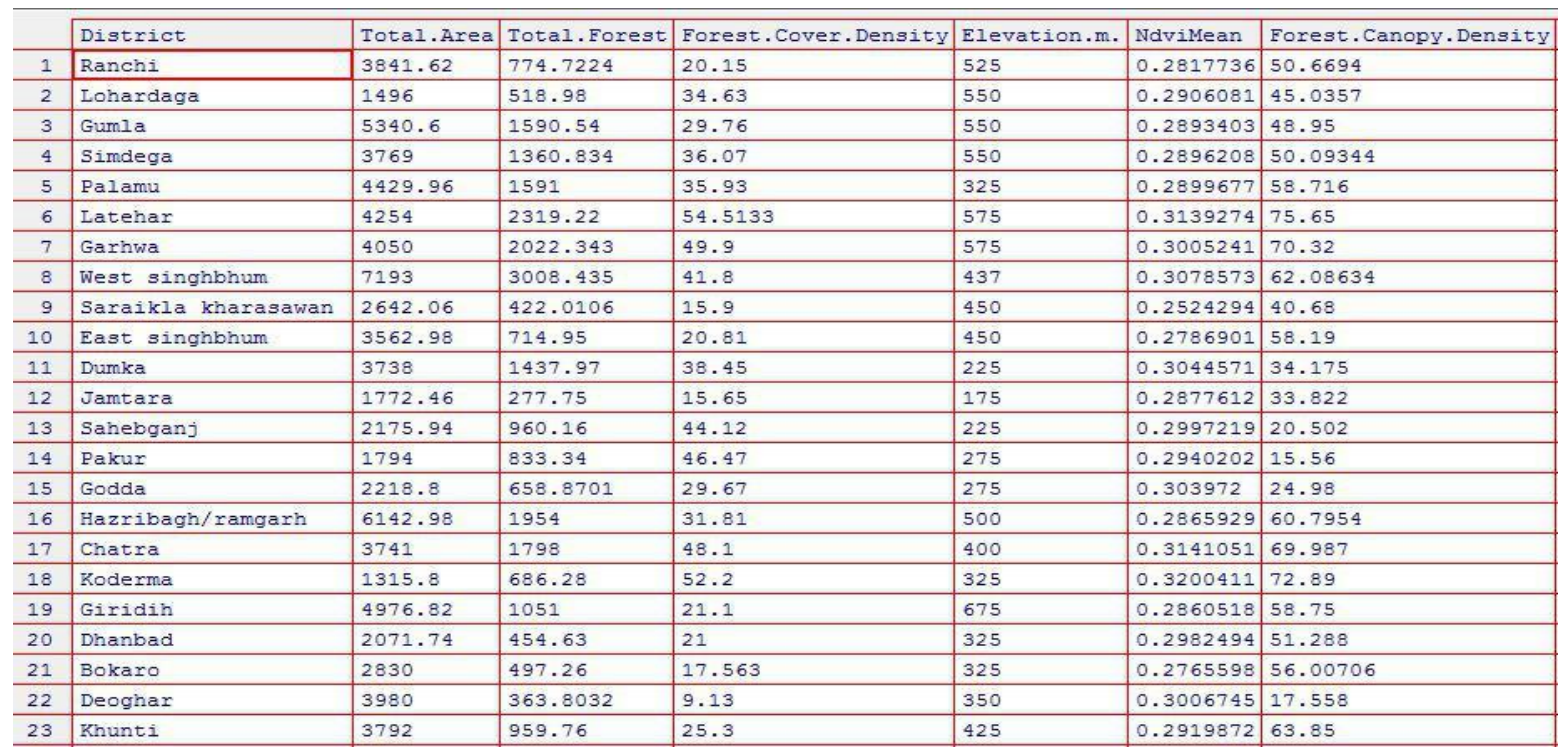

Figure5. Result in R (STATISTICAL SOFTWARE)

By analyzing the above map, we observe that there is a maximum forest given by the FCD model, whereas other two techniques which applied on ASTER DEM and LANDSAT 8: Forest cover Map Elevation Map gives approx. extent of forest by interpretation, which is not as good as FCD model. Forest cover loss is going on in large rate in the test area mainly due to deforestation and expansion of agricultural land, which can easily be monitored using the biophysical modelling in conjunction with the satellite image. 
Assessment of Forest Cover Conditions and Canopy Density using Remote Sensing and GIS Techniques in Parts of Jharkhand State

\section{CONCLUSION}

Forest cover density variation was found to be in tune with NDVI variation showing increase in forest density. Hence, indicating healthy forest conditions in the study area. It was also observed that the elevation is not compatible with the forest cover density due to fluctuation in elevation range.

For the Jharkhand state as a whole, the correlation coefficient value between Forest Canopy Density model and forest cover check shows a value of 0.33 . For the forest variations in larger scale, similar resolution of the ASTER DEM data can be used. FCD Model shall be helpful in locating regions with higher Forest regions density with ease.

\section{REFERENCE}

[1] Achard, F., Eva,H., \& Mayaux, P. Tropical forest mapping from coarse spatial resolution satellitedata: pro-duction and accuracy assessment issues. International Journal of Remote Sensing, 22(14), 27412762. (2001).

[2] Azizia, Z., A. Najafi, and H. Sohrabia."Forest Canopy Density Estimating Using Satellite Images." Proc. of The International Society for Photogrammetry and Remote Sensing Congress Commission VIII, Beijing, China, July. 2008.

[3] Banerjee. K, Panda.S, Jatisankar.B and Jain.M.K." Forest Canopy Density Mapping Using Advance Geospatial Technique. "IJISET - International Journal of Innovative Science, Engineering \& Technology, Vol. 1 Issue 7, September 2014.

[4] Blodgett,C., Jakubauskas, M., Price, K. and Martinko, E. Remote sensing-based geostatistical modeling of forest canopy structure, Pros. ASPRS Annual Conference,held at Washington DC form May 22-26, 2000.

[5] Chander, G.,Markham, B.L., \& Helder, D. L.Summary of current radiometric calibration coefficients for Landsat MSS, TM, ETM+, and EO-1 ALI sensors. Remote Sensing of Environment, 113 (2009), 893-903.
[6] Chandrashekhar, M.B., Saran,S., Raju, P. L. N., \& Roy, P.S. Forest canopy density stratification: How relevant is biophysical spectral response modelling approach? Geocarto International, 20(1), 15-21. .(2005)

[7] Chakraborty, K.Vegetation change detection in Barak Basin. Current Science, 96, 1236-1242. (2009).

[8] Chander, G., Markham, B.L.,\& Helder, D.L.Summary of current radiometric calibration coefficients for Landsat MSS, TM, ETM+, and EO-1 ALI sensors. Remote Sensing of Environment, 113(2009), 893-903

[9] Chavez, P. S.Radiometric calibration of Landsat Thematic Mapper multi-spectral images.

[10] Photogrammetric Engineering and Remote Sensing, 55, 1285-1294 (1989).

[11] Curran,P. J.Multispectral remote sensing of vegetation amount .Progress in Physical Geography, 4, 315-341.FAO.(2010).

[12] D'arrigo, R.D., et al. "Correlation between maximum latewood density of annual tree rings and NDVI based estimates of forest productivity." International Journal of Remote Sensing 21.11 (2000): 23292336

[13] Deka, Jyotishman, Om Prakash Tripathi, and Mohamed Latif Khan."Implementation of forest canopydensity model to monitor tropical deforestation." Journal of the Indian Society of Remote Sensing 41.2(2013): 469-475.

[14] Dissing, Dorte, and David L. Verbyla. "Spatial patterns of lightning strikes in interior Alaska and their relations to elevation and vegetation."Canadian Journal of Forest Research 33.5(2003): 770-782 
Assessment of Forest Cover Conditions and Canopy Density using Remote Sensing and GIS Techniques in Parts of Jharkhand State

\section{AUTHOR's BIOGRAPHY}

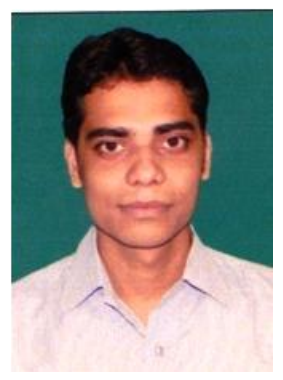

Jai Kumar, was born in Bokaro, India, in 1990. He received the Bachelor of geography (Hons)from the ST. Xavier College, Ranchi, India, in 2010, and the Master of geography from V.B.U hazaribag,india in,2013 and M.Tech. degrees in Remote Sensing from the Birla Institute of Technology (BIT) Ranchi, Jharkhand, India, in 2013 and 2015 respectively. He has a keen interest in Remote Sensing and GIS.

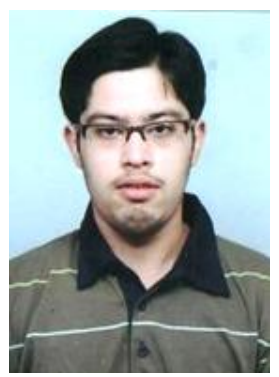

Paras Talwar, was born in Delhi, India, in 1990. He received the B.Sc (Hons) degree in Electronics from the University of Delhi, India, in 2011, and Master degrees in Electronics and Communication from Devi Ahilya Vishwavidyalaya, Indore,M.P india ,in 2013. M.Tech in Remote Sensing from the Birla Institute of Technology (BIT) Ranchi, Jharkhand, India, in 2015 respectively. He has a keen interest in Open Source Geographical Information System softwares .

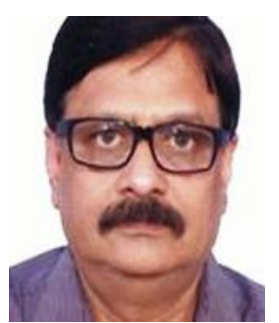

A.P Krishna, have 13 and 30 years of experience in teaching and research respectively. He has received many awards and attends many national and international conferences. He is also the Life member of nine professional bodies. Currently, he is the HOD of Remote Sensing Department in Birla Institute of Technology, Ranchi, Jharkhand.

Citation: Kumar, Jai et al. "Assessment of Forest Cover Conditions and Canopy Density Using Remote Sensing and GIS Techniques in Parts Of Jharkhand State". International Journal of Research In Agriculture and Forestry, vol 4, no. 4, 2017, pp. 12-18.

Copyright: (C) 2017 Kumar, Jai et al. This is an open-access article distributed under the terms of the Creative Commons Attribution License, which permits unrestricted use, distribution, and reproduction in any medium, provided the original author and source are credited. 